\title{
S25. New discoveries in dopamine (supported by an educational grant from Astra S)
}

DUAL EFFECTS OF ANTIPSYCHOTICS THROUGH DOPAMINE $D_{2}$ AND D 3 RECEPTORS

P Sokoloff, D Levesquc, M-P Martres, N Griffon, C Pilon, F Sautel and J-C Scluwartz Unite de Neurobiologie et de Pharmacologie de l'INSERM. Paris. France, J Diaz and V Dimitriadou, Laboratoire de Physiologie, Université René Descartes, Paris. firance. P Simon and I Costentin, Laboratoire de Pharmacodynamic. ULR de Midecine et de P'harmacie, Rouen. France. A Mann and CG Wermuth, Laboratoire de Pharmacochimie Moléculaire, Centre de Neurachimie, Sirasbourg. France.

Dopamine $D_{2}$ and $D_{3}$ recejtors $\left(D_{2} R\right.$ and $\left.D_{3} R\right)$ are boll blocked by antipsychotics. In a transfected neuroblastoma cell linc, $D_{3} R$ increascs mitogenesis through a mechanism independant of adenylyl cyclase inhibition and of stimulation of phospholipase C. $D_{3} R$ activation also induces Fos immunoreactivity: suygesting that $D_{3} R$ may activate genes that contain an AP-1 domain. such as neurotensin (NT) gene. The distributions of $D_{2} R, D_{3} R$ and $N T$ mRNAs assessed in in sill lubridization sudies were compared in nuclcus accumbens. Which las becn subdivided into a 'corc' part, structurally and functionally related to striatum and into a "slcll" part, possibly involved in many aspects of cmotion, cognition and motivated belaviour through a control fecdback loop with the prefrontal cortex.. $\mathrm{D}_{2} \mathrm{R}$ mRNA is expressed mostly in the core and marginally in the shell, whereas the $D_{3} R$ mRNA is mostly present in the shell, where its distribution ovcrlaps that of NT mRNA. Co-hybridization studies showed that the $D_{3} R$ mRNA is expressed by NT neurons. Treatment by haloperidol and other $D_{2} R / D_{3} R$ antagonists increase NT mRNA in the $D_{2} R$ ImRNA cxpressing areas, but decrcased NT mRNA in the $D_{3} R$ mRNA cxpressing areas, suggesting opposite effects of these two receptors on NT expression. In addition. $D_{3} R$ mRNA is not modificd by chronic haloperidol treatment, in accordance with its participation in the antipsychotic drug treatment, for which there is no tolerance. D0 779 , a partially scloctive $D_{3} R$ antagonist produces paradoxical behavioral activations in rodents, suggesting that DA exerts tonic inhibition on locomotor behaviours via $D_{3} R$, an effect opposite to that $D A$ exert via $D_{2} R$. Hence, by blocking two opposing receptors, antipsychotics may have both inhibitory and stimulating effects. The greater efficiency of these drugs against positive symptoms of schizophrenia than negative symptoms might be related to the $\mathrm{D}_{2} \mathrm{R}$-preferring properties of the available antipsychotics. This hypothesis will be evaluated in clinical assessment of $D_{3} R$-preferring antagonists. Supported by the Biomedical and Health Research Programme LEC C792-10,80
POSSIBLE MECHANISMS UNDERLYING THE ATYPICAL ANTIPSYCHOTIC PROFILE OF CLOZAPINE AND REMOXIPRIDE Sven Ove ögren Division of Histology, Dept. of Neuroscience, The Karolinska Institute, S-171 77 Stockholm, Sweden.

The atypical antipsychotic drug clozapine produces significantly less extrapyramidal side-effects (EPS) than typical neuroleptic drugs (haloperidol). Several hypotheses have been proposed to explain the atypical action of clozapine including a combined blocking action at DA and muscarinic cholinergic receptors or a combined blocking effect at DA and serotonin (5-HT-2) receptors. Recent in vitro receptor binding data have led to the suggestion that the unique action of clozapine is due to a preferential action on a subtype of the DA D-2 receptor, i.e. the D-4 receptor. The development of the selective DA D-2 antagonist remoxipride as an efficacious antipsychotic agent with a low EPS potential challenges current concepts on mechanisms underlying atypical antipsychotic activity. Both clozapine and remoxipride display an atypical antipsychotic profile in the rat, since they preferentially block behaviours associated with the mesolimbic compared to those associated with the nigroneostriatal DA system. Hovever, unlike clozapine, remoxipride lacks affinity for muscarinic, 5-HT-2, DA D-1 and DA D-4 receptors and, unlike most other antipsychotic drugs, remoxipride has negligible affinity for the DA D-3 receptor (Malmberg et al. 1993) (Ögren et al. 1994). Moreover, recent studies based on studies of DA D-2 receptor inactivation using N-ethoxycarbony 1-2-ethoxy-1,2-dihydroxyquinoline indicate that remoxipride in vivo act on a subpopulation of DA D-2 receptors. Different mechanisms vere found to underlie the atypical antipsychotic profile of clozapine and remoxipride.

\section{References}

Malmberg et al. (1993) Mol. Pharmacol. 43:749-754.

Ögren et al. (1994) Neuroscience (in press) 
AUTORADIOGRAPIIC STUDIES OF EXTRA-STRIATAL DOPAMINE RECEPTORS USING [ 125 I]EPIDEPRIDE AND ANALOGUES Hakan Hall, Lars Farde. Christer Halldin, Göran Sedvall Department of Clinical Neuroscience, Psychiatry and Psychology Section. Karolinska Hospital, S-17176 STOCKHOLM, SWEDEN

The highest densities of dopamine- $D_{2}$ receptors in the mammalian brain are found in the striatum ( $\mathrm{N}$. caudatus and putamen). There is growing evidence that the extra-striatal dopamine- $\mathrm{D}_{2}$ receptors, in spite of the low density, play important roles in dopaminergic neurotransmission. Previously used radioligands have too low affinity for visualizing these receptors. Recently developed high potency benzamide ligands, such as [125I]epidepride and [ ${ }^{125}$ I]NCQ 298 , give the potential to quantitatively study the extra-striatal dopamine- $\mathrm{D}_{2}$ receptors with radioligand binding and autoradiography.

Both epidepride and NCQ 298 have been used in animal in vivo and in vitro studies, as well as in SPECT in monkeys. NCQ 298 labels predominantly striatal areas, although receptors in cortex and hippocampus also have been visualized, whereas epidepride in addition to the striatal labelling also labels extra-striatal receptors.

In recent PET examinations, Farde et al. have shown using PET-techniques, that the benzamide [ $\left.{ }^{1} \mathrm{C}\right] \mathrm{FLB} 457$, which is the bromine analogue to epidepride, labels dopamine- $\mathrm{D}_{2}$ receptors not only in the nucleus caudatus and putamen but also in extra-striatal areas of the human brain, such as in the thalamus and amygdala.

In this presentation we report on the distribution and pharmacology of dopamine- $\mathrm{D}_{2}$ receptors using human whole hemisphere autoradiography with [ ${ }^{125}$ I] epidepride. The results indicate that $\left[{ }^{125} \mathrm{I}\right]$ epidepride labels receptors in nucleus caudatus, putamen and pallidum and also in extrastriatal areas such as thalamus and the substantia nigra. The intensity of the labelling is different in the various nuclei of the thalamus. The highest densities are seen in the nucleus parataenialis and nucleus anteroprincipalis, with lower binding in nucleus pulvinaris and nucleus centralis. Moreover, ${ }^{125}$ I $]$ epidepride also accumulates in cortical layers. The binding in striatal as well as in extra-striatal areas is blocked by dopamine- $\mathrm{D}_{2}$ receptor antagonists

\section{FAILURE TO DEMONSTRATE ANTIPSYCHOTIC EFFECT OF THE DOPAMINE $D_{1}$-RECEPTOR ANTAGONIST} SCH 39166 IN SCHIZOPHRENIC PATIENTS

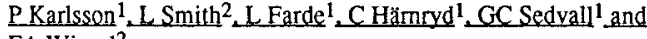 EA Wiesel ${ }^{2}$}

${ }^{1}$ Department of Clinical Neuroscience, Psychiatry and Psychology Section, Karolinska Hospital, S-171 76 Stockholm, Sweden, ${ }^{2}$ Department of Psychiatry, Akademiska Hospital, S-751 85 Uppsala, Sweden

SCH 39166 is the first selective $D_{t}$-receptor antagonist developed for clinical trials. Behavioural, biochemical and electrophysiological effects in animal models indicate that dopamine $D_{1}$-receptor antagonists may be effective to treat schizophrenia. PET-experiments with ${ }^{11} \mathrm{C}$ labelled SCH 39166 indicate stereoselective binding to $\mathrm{D}_{1}$-dopamine receptors in the human brain. More than $70 \%$ of specific [ ${ }^{11} \mathrm{C}$ SSCH 39166 binding in the basal ganglia was blocked after treatement of healthy men with single oral doses of $100 \mathrm{mg} \mathrm{SCH} 39166$.

To examine safety, tolerability and potential antipsychotic effect we gave SCH 39166 to 17 acutely ill drug free schizophrenic patients (DSMMIR) in an open 4 week study. Doses were escalated according to fixed schedule from 10 to $100 \mathrm{mg}$ b.i.d. during 17 days. In eight patients the drug was withdrawn due to deterioration or failure to comply. In the nine patients participating for more than 2 weeks, none had an apparent reduction of BPRS or CGI scores. Side effects were emesis and akathisia in single patients. After withdrawal of SCH 39166 most of the patients improved when treated with conventional neuroleptics.

The result of the study does not support the prediction that selective $D_{1}$ dopamine receptor antagonism will produce antipsychotic effects in schizophrenia. Since most of the patients responded to conventional neuroleptics the results further emphasise the critical role of $\mathrm{D}_{2}$-antagonism as principle for antipsychotic action. The results do not preclude that a combined $D_{1}$ - and $D_{2}$ - receptor antagonism may have synergistic ameliorative effects in schizophrenia.

Supported by NIMH, Swedish Medical Research Council and ScheringPlough
PET-STUDIES ON EXTRASTRIATAL DOPAMINE RECEPTORS USING [11 C]FLB457

Lars Farde, Christer Halldin Svante Nyberg. Håkan Hall' Stefan Pauli. Göran Sedvall, *Nina Mohell and *David Jackson Dept of Clinical Neuroscience, Karolinska Hospital, S-171 76 Stockholm, Sweden, and *Astra Arcus AB, Sweden.

Studies on brain biochemistry, morphology and physiology indicate that the function of extrastriatal brain regions may be disturbed in patients with schizophrenia. Positron Emission Tomography (PET) has hitherto been used for quantitative determination of dopamine receptors in the major basal ganglia, which are large brain structures with a high dopamine receptor density. In extrastriatal regions the potential for PET-examination is limited by the low receptor densities, which are $10-100$ times lower than in the basal ganglia.

${ }^{1}{ }^{1}$ C]FLB 457 is a substituted benzamide which has the extremely high affinity (Kd) of 20 pM for D2-dopamine receptors in vitro. FLB 457 has virtually no affinity for any other transmitter receptor besides D3. $\left.{ }^{11} \mathrm{C}\right] \mathrm{FLB} 457$ was prepared by $\mathrm{O}$-alkylation from $\left[{ }^{11} \mathrm{C}\right.$ methyl iodide. In initial experiments [ ${ }^{11}$ C]FLB 457 was injected into cynomolgus monkeys. There was a high uptake of radioactivity in the striatum. Striatal but not cerebellar radioactivity was displaced after i.v. injection of raclopride (2 $\mathrm{mg} / \mathrm{kg}$ ). In PET-studies on 5 healthy human subjects [ $\left.{ }^{1}{ }^{1} \mathrm{C}\right]$ FLB457 accumulated not only in the basal ganglia but also in several extra-striatal regions. Uptake in the thalamus, amygdala, substantia nigra, colliculus and neocortex was 2-5 times higher than in the cerebellum.

In extrastriatal brain regions radioactivity reached a plateau at about 50 minutes after injection. Assuming that radioactivity in the cerebellum reflects the level of free and non-specific binding, the specific binding in extrastriatal regions was on a maximal level within 60 minutes. Specific

${ }^{11}$ C $] F L B ~ 457$ binding should thus be suitable for a quantitative equilibrium analysis of extrastriatal dopamine receptor densities. ${ }^{1}{ }^{1}$ C]FLB 457 binding was examined in 2 patients treated with conventional doses of haloperidol. Specific $\left[{ }^{11^{1}}\right.$ ]FLB457 binding in extrastriatal regions was $70 \%$ lower than in the control subjects. This is the first demonstration that antipsychotic drug treatment has effect on dopamine receptors in extra-striatal regions. 